\title{
Results of Burr Hole and Open or Closed Suction Drainage for Chronic Subdural Hematomas in Adults
}

\author{
B.K.A. Weir
}

\begin{abstract}
SUMMARY: Chronic subdural hematomas in adults are not technically difficult to treat. They probably constitute one of the most common potentially curable lesions with which the average neurosurgeon deals. Despite this (or perhaps because of it) numerous treatments, radically differing from one another, have been advocated. Fine judgement is called for in deciding whether or not to operate in the first instance, make a flap or one or more burr or twist drill holes, use a drain, employ suction, inflate the brain, leave the bone flap out. In a personal series of 71 chronic subdural hematomas, 46 were treated with a red rubber catheter drain through a burr hole and 23 with a closed system suction drain. The results of this series suggest that closed system suction drainage through a single burr hole is the better of the two techniques. It has important theoretical advantages and the procedure is simple and fast. The complication rate is low and patients have a shortened postoperative hospital stay.
\end{abstract}

RÉSUMÉ: Il n'est pas techniquement difficile de traiter les hématomes subduraux chroniques de l'adulte. En fait il s'agit probablement de la lésion au meilleur pronostic que rencontre le neurochirurgien moyen. Malgré ces faits plusieurs traitements ont été préconisés. Ainsi il faut utiliser son jugement pour décider: s'il faut opérer, s’il faut ouvrir une fenêtre ou faire un ou plusieurs trous de trépan, s’il faut utiliser un drain, la suction, gonfler le cerveau et laisser la fenêtre ouverte. Dans une série personnelle de 71 cas d'hématome chronique, nous en avons traité 46 avec un drain-catheter en caoutchouc rouge passant par un trou de trépan, et 23 par un drain-suction en système fermé. Nos résultats suggèrent que le drainage par suction en système fermé, par un simple trou de trépan, est la meilleure des deux techniques. Il existe des avantages théoriques certains et, de plus, la procédure est simple, rapide, avec peu de complications et elle permet de réduire la durée du séjour hospitalier.

Can.J. Neurol. Sci. 1983; 10:22-26

A wide variety of techniques have been advocated for dealing with chronic subdural hematomas. It has been difficult to compare the results of different series because of lack of precision in the definition of what constitutes a "chronic" hematoma. In this series the definition is restricted to include only patients in whom (i) there is no known history of severe head injury within seven days prior to surgery or (ii) symptoms have been present for at least one week or the exact time is unknown. These criteria exclude all cases with significant primary parenchymal damage of traumatic origin which have a more severe course and a totally different treatment, as well as acute intracranial hemorrhage with rupture into the subdural space. This study reviews all the author's operated cases.

\section{CLINICAL MATERIAL AND METHODS}

Hospital and office records were reviewed to collect data on all cases of chronic subdural hematomas personally operated on in the period 1967 to early 1982 . The cases met the definition of "chronic" given above. Specifically excluded were subdural hygromas and hematomas associated with depressed skull fractures and/or parenchymal brain injuries.

This series includes seventy-one cases. One had an initial craniotomy (the first patient in the series) and another had a burr hole only without insertion of a drain. The groups treated with burr hole and catheter drainage or burr hole and closed suction drainage using the Jackson-Pratt drain, were compared with respect to deaths, reoperation rate and postoperative hospital stay.

Until 1977 a single burr hole was usually made over the parietal convexity and, after the liquid contents were aspirated, a red-rubber catheter with multiple holes was placed in the hematoma and left to drain into the head dressing. A change was made to the closed suction drainage system since it was felt it would be easier to keep sterile and it would facilitate more efficient drainage of the residual hematoma since it would be independent of gravity. With the advent of CT scanning, the suction drain was thought to be a more efficient method of evacuating the hematoma on the basis of the direct visualization of the reduction in hematoma size and resolution of brain shifts. The suction drainage system is illustrated in Figure 1.

\section{RESULTS}

For the total series of 71 cases of chronic subdural hematomas the infection rate was $1.4 \%$, the reoperation rate $12.6 \%$ and the mortality rate $3 \%$. The outcome for the groups treated by red rubber catheter open drainage or Jackson-Pratt closed suction drain (Jackson and Pratt, 1971 ) is presented in Table 1.

The one fatality in the catheter drainage (pre-1977) series

From the Division of Neurosurgery, University of Alberta.

Received July 15, 1982. Accepted for publication November 15, 1982.

Address reprint requests to Dr. B.K.A. Weir, Division of Neurosurgery, 11 th Floor, Clinical Sciences Building, The University of Alberta,

Edmonton, Alberta T6G 2G3. 
was a 23 year old hemophiliac who had a history of headaches of 7 to 8 days duration. Despite cryoprecipitate therapy and reoperation a few hours following the initial burr hole and drainage, he died. In the Jackson-Pratt drainage series the only death was an 86 year old male who had had a massive stroke 15 years prior to this illness, and who arrived obtunded and died of pneumonia a few days following surgery despite the use of antibiotics and chest physiotherapy. The cause of death was not recurrent or residual subdural hematoma.

There were no infections after the closed system JacksonPratt drain was introduced. The only infection in the red rubber catheter drainage series occurred in a patient who arrived in hospital with a recently placed ventriculoatrial shunt complicated by a subdural hematoma. A couple of months following the burr hole and placement of a subdural drain the patient had a repeat burr hole and shortly thereafter at a fourth operation an empyema was drained. It is impossible to say when the subdural was contaminated.

The change in technique adopted in 1977 resulted in a marked reduction in reoperation rate. In addition to this there was a considerably shorter hospitalization associated with the Jackson-Pratt drainage system.

\section{DISCUSSION}

A selective summary of the vast literature on surgery for chronic subdural hematomas is presented in Tables 2 and 3. While different series were not directly comparable because of inclusion of different types of cases with varying degrees of neurological deterioration and associated systemic illnesses, it is clear that many different approaches can produce good results and are associated with similar problems. In their review of complications following treatment of chronic subdural hematomas Tindall et al (1976) found reaccumulation rates of $8 \%$ to $20 \%$ and infection rates around $4 \%$.

TABLE 1

Results of Treatment of Chronic Subdural Hematoma Using Two Different Methods*

\begin{tabular}{lcc}
\hline & $\begin{array}{c}\text { Burr Hole and } \\
\text { Catheter } \\
\text { Drainage }\end{array}$ & $\begin{array}{c}\text { Burr Hole and } \\
\text { Jackson-Pratt } \\
\text { Drainage }\end{array}$ \\
\hline Number & 46 & 23 \\
Years & $1967-1977$ & $1977-1982$ \\
Deaths & $1(2.2 \%)$ & $1(4.2 \%)$ \\
Infections & $1(2.2 \%)$ & $0(0 \%)$ \\
Reoperations & $8(17 \%)$ & $* * 0(0 \%)$ \\
Postoperative stay & $18 \pm 5$ days & $* * 15 \pm 7$ days \\
(mean \pm SD) & $13(28 \%)$ & $14(61 \%)$ \\
$\leq 7$ days & $18(39 \%)$ & $7(30 \%)$ \\
$8-13$ days & $15(33 \%)$ & $2(9 \%)$ \\
$\geq 14$ days &
\end{tabular}

* One additional patient had a burr hole without a drain and one patient had a craniotomy.

** $p<0.05$ (Chi-square test)

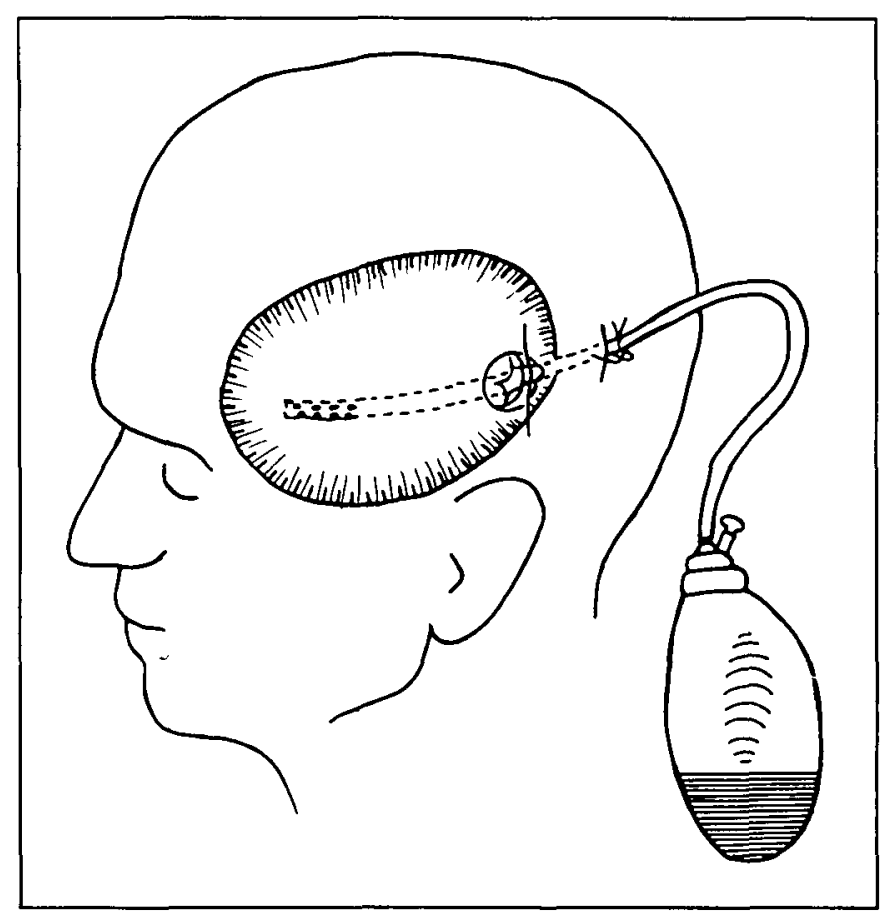

Figure 1 - Schematic illustration of the closed system suction drainage lying in the hematoma cavity. The system is placed through a single burr hole and exits via a posterior stab wound.

Since the use of craniotomy and craniectomy are not clearly more effective and since they entail greater potential complications for the patient, this method of treatment should no longer be employed as a primary surgical therapy of chronic subdural hematomas. As far back as 1935, Gardner gave up craniotomy in favor of a $1 \frac{1}{2} \mathrm{~cm}$ trephine and found that patients recovered as quickly and completely as they would have with treatment by craniotomy. Dandy (Kunkel, 1939) also gradually lessened the size of his cranial exposure without seeing any difference in results and commented on the fact that cures could be prompt and unequivocal even though only a fraction of the membranes were removed. The Mayo Clinic experience was reviewed by Svien (1964) and it was concluded that burr hole evacuation yielded superior results to craniotomy and membranectomy.

The use of twist drill rather than burr hole has little to recommend it. With a burr hole one can inspect the clot directly and there is greater safety in inserting the drain. A twist drill hole is not large enough to permit insertion of the Jackson-Pratt or similar drain. A twist drill might be considered in extremely emergent or primitive circumstances.

One burr hole is as effective as two. A post burr hole craniotomy was not necessary in these 70 cases treated initially with burr holes. One can judge via the burr hole if there is a tenacious organized clot and, in that case, few would dispute the necessity for turning a flap and carrying out evacuation of the clot. The presence of some clot in a liquid hematoma however is not an indication for turning a flap.

The advantages of the closed suction system are: 1) drainage can be carried out gradually to avoid postoperative intracerebral hematomas (Modesti et al, 
TABLE 2

Results with Drainage Treatments for Chronic Subdural Hematoma

\begin{tabular}{|c|c|c|c|c|c|c|}
\hline Author & Year & $\begin{array}{c}\text { Number } \\
\text { of } \\
\text { Cases }\end{array}$ & $\begin{array}{c}\text { Average } \\
\text { Age }\end{array}$ & Infection & Reoperation & Mortality \\
\hline \multicolumn{7}{|c|}{ Burr Hole(s) and Closed System Suction Drainage } \\
\hline Weir & 1982 & 23 & 62 & $0 \%$ & $0 \%$ & $4 \%$ \\
\hline Markwalder & 1981 & 32 & 61 & $0 \%$ & $3 \%$ & $0 \%$ \\
\hline \multicolumn{7}{|c|}{ Burr Hole(s) and Closed System Gravity Drainage } \\
\hline Gilsbach & 1980 & 51 & 56 & $0 \%$ & $22 \%$ & $2 \%$ \\
\hline \multicolumn{7}{|c|}{ Burr Hole(s) and Simple Drainage } \\
\hline Weir & 1982 & 46 & 56 & $2 \%$ & $17 \%$ & $2 \%$ \\
\hline Tabaddor & 1977 & 22 & - & $0 \%$ & - & $23 \%$ \\
\hline Jamieson & 1972 & 249 & - & - & - & $11 \%$ \\
\hline Svein & 1964 & 50 & - & $4 \%$ & $20 \%$ & $7 \%$ \\
\hline McKissock & 1960 & 184 & - & - & - & $6 \%$ \\
\hline Gardner & 1935 & 8 & 46 & - & - & $25 \%$ \\
\hline Fleming & 1932 & 8 & 43 & $13 \%$ & $25 \%$ & $13 \%$ \\
\hline \multicolumn{7}{|c|}{ Burr Hole(s) and Long Term External Drainage } \\
\hline Matricali & 1975 & 7 & 50 & - & $14 \%$ & $0 \%$ \\
\hline Yashon & 1971 & 8 & 75 & $0 \%$ & $0 \%$ & $38 \%$ \\
\hline \multicolumn{7}{|c|}{ Twist Drill Hole and Drainage } \\
\hline Tabaddor & 1977 & 21 & - & - & $0 \%$ & $10 \%$ \\
\hline Hubschmann & 1980 & 22 & 65 & $0 \%$ & $9 \%$ & $0 \%$ \\
\hline \multicolumn{7}{|c|}{ Burr Hole and Implanted Silastic Device for Percutaneous Repeat Drainage } \\
\hline Arbit & 1980 & 25 & - & $0 \%$ & $4 \%$ & $0 \%$ \\
\hline
\end{tabular}

TABLE 3

Results Without Drains in Treatment for Chronic Subdural Hematoma

\begin{tabular}{|c|c|c|c|c|c|c|}
\hline Author & Year & $\begin{array}{c}\text { Number } \\
\text { of } \\
\text { Cases }\end{array}$ & $\begin{array}{c}\text { Average } \\
\text { Age }\end{array}$ & Infection & Reoperation & Mortality \\
\hline \multicolumn{7}{|c|}{ Burr Hole(s) Without Drainage } \\
\hline Ohaegbulam & 1981 & 132 & - & - & - & $.8 \%$ \\
\hline \multicolumn{7}{|c|}{ B urr Hole(s) and Intraventricular or Lumbar Saline Injection } \\
\hline Cameron & 1978 & $45 / 112$ & 56 & $1 \%$ & $3 \%$ & $4 \% *$ \\
\hline Robinson & 1955 & $14 / 28$ & - & - & $14 \%$ & $4 \% *$ \\
\hline \multicolumn{7}{|c|}{ Craniectomy or Craniotomy } \\
\hline Tabaddor & 1977 & 28 & - & - & - & $29 \%$ \\
\hline Svein & 1964 & 19 & - & $11 \%$ & $37 \%$ & $7 \%$ \\
\hline Vieth & 1966 & 38 & - & $3 \%$ & $8 \%$ & $7 \%$ \\
\hline McKissock & 1960 & 12 & - & - & - & $8 \%$ \\
\hline Kunkel & 1939 & 48 & 41 & $2 \%$ & $4 \%$ & $4 \%$ \\
\hline Gardner & 1935 & 12 & 38 & - & - & $0 \%$ \\
\hline Putnam & 1925 & 10 & - & $0 \%$ & $30 \%$ & $30 \%$ \\
\hline
\end{tabular}


1982); 2) there is less chance of bacterial contamination of the subdural space; 3) air can be prevented from entering the subdural space and producing a tension pneumocephalus. Since the results with closed suction drainage are as good or better than the results of saline or mock CSF injection via a lumbar puncture or a ventricular catheterization, there can now be little justification for these more radical interventions (Cameron, 1978; Hancock, 1965; Robinson, 1955).

In a recent series from Nigeria of 132 patients with purely traumatic subdurals of more than 3 days duration, excellent results were reported using only burr hole evacuation without drainage (Ohaegbulem, 1981). He recommends the use of this treatment in areas where CT scanning, ambulance, surgical and anesthetic facilities are lacking or inferior. There is little doubt that many patients can be adequately treated by this operation. It is unlikely that as high a percentage of patients in the present series would have recovered without drainage considering the large volume of fluid drained in some cases over the day or two following the initial burr hole. It is uncertain that the results in the African population can be extrapolated directly to our North American population of older patients with hematomas which are not purely traumatic in origin and with a high incidence of alcoholism and medical disease.

At the other extreme of operative complexity, a recent report (Tyson et al, 1980) presented 48 adult patients with chronic subdural hematomas in whom $15 \%$ continued to demonstrate severe neurological dysfunction, or suffered deterioration after multiple burr holes and percutaneous drainage. They were treated by bone flap removal and duroplasty. This was not necessary in any of the 71 consecutive cases reported here and Markwalder et al (1981) resorted to craniotomy and membranectomy in only 1 of their 31 cases (3\%). The experience of Tyson et al therefore appears to be highly atypical.

The CT scan has greatly simplified the management of chronic subdurals. Bilateral hematomas can be diagnosed preoperatively and both can be evacuated simultaneously which is the safest way to manage them (Kaste et al, 1979). In addition, the postoperative CT scan may show large quantities of air in the cavity which can account for a delay in recovery. The fact that brain may not obliterate the subdural space for some weeks in patients who are recovering uneventfully is also of importance (Markwalder et al, 1981). In patients who are doing poorly, postoperative edema or hematoma in the brain subjacent to the hematoma can be differentiated from a recurrence and treated appropriately. From older accounts in the literature (Gardner, 1935; Kunkel, 1939) this may have been a common cause of death.

The advantages of the Jackson-Pratt drain are that it is a closed system, independent of gravity, non-collapsible and the part in the subdural space is supple. The reservoir permits measurement, analysis and culture of the hematoma contents. It is less complicated than the closed system of Gilsbach et al (1980) which is gravity dependent.

There has been no preoperatively randomized trial of one type of therapy versus another in the treatment of chronic subdural hematomas. Since mortality is so low in contemporary series, it would require very large numbers of patients to demonstrate unequivocally that suction drainage with a closed system is superior to a simple burr hole. Combining the results in the present series and the results of Markwalder et al. (1981) indicates that the closed suction method of treatment was associated with zero infection rate, a $2 \%$ reoperation rate and a $2 \%$ mortality rate in 55 cases. This method can therefore be recommended strongly, if not absolutely, as the current treatment of choice. The data reviewed here suggest that placement of a single burr hole and insertion of a drain for one or two days should be the initial procedure of choice.

\section{REFERENCES}

Arbit, E., Patterson, R.H., Fraser, R.A.R. (1980): An implantable subdural drain for treatment of chronic subdural hematoma. Surgical Neurology, 15: 175-177.

Cameron, M.M. (1978): Chronic subdural hematoma: a review of 114 cases. Journal of Neurology, Neurosurgery and Psychiatry, 41:834-839.

Fleming, H.W., Jones, O.W. (1932): Chronic subdural hematoma. Simple drainage as a method of treatment; report of eight cases. Surgery, Gynecology and Obstetrics, 54:81-87.

Gardner, W.J. (1935): Traumatic subdural hematoma; a report of twenty-two cases. Ohio State Medical Journal, 18: $660-665$.

Gilsbach, J., Eggert, H.-R., Harders, A. (1980): Externe geschlossene drainage behandlung des chronischen subdural hamatoms nach bohr loch trepanation. Unfall chirurgie 6: 183-186.

Hancock, D.O. (1965): Cerebral collapse associated with chronic subdural hematoma in adults. A comparison of two methods of treatment. Lancet, 1: 633-634.

Hubschmann, O.R. (1980): Twist drill craniostomy in the treatment of chronic and subacute subdural hematomas in severely ill and elderly patients. Neurosurgery, $6: 233-$ 236.

Jackson, F.E., Pratt, R.A. (1971): Technical report: a silicone rubber suction drain for drainage of subdural hematomas. Surgery, 70: 578-579.

Jamieson, K.G., Yelland, J.D.N. (1972): Surgically treated traumatic subdural hematomas. Journal of Neurosurgery, 37: 137-149.

Kaste, M., Waltimo, O., Heiskanen, O. (1979): Chronic bilateral subdural hematomas in adults. Acta Neurochirurgica (Wien), 48: 231-236.

Kunkel, P.A., Dandy, W.E. (1939): Archives of Surgery, 38: 24-54.

Markwalder, T.-M., Steinsiepe, K.F., Rohner, M., Reichenbach, W., Markwalder, H. (1981): Time course of chronic subdural hematomas after burr-hole craniostomy and closed-system drainage. Journal of Neurosurgery, 55: 390-396.

Matricali, B. (1975): Subdural suction drainage of haematomas. Surgical Neurology, 3: 245-246.

McKissock, W., Richardson, A., Bloom, W.H. (1960): Subdural haematoma. A review of 389 cases. Lancet, 1: 1365-1369. 
Modesti, L.M., Hodge, C.J., Barnwell, M.L. (1982): Intracerebral hematoma after evacuation of chronic extracerebral fluid collections. Neurosurgery, 10:689-693.

Ohaegbulam, S.C. (1981): Surgically treated traumatic subacute and chronic subdural haematomas: a review of 132 cases. Injury, 13:23-26.

Putnam, T.J., Cushing, H. (1925): Chronic subdural haematoma; its pathology, its relation to pachymeningitis haemorrhagica and its surgical treatment. Archives of Surgery, 1: 329-393.

Robinson, R.G. (1955): The treatment of subacute and chronic subdural hematomas. British Medical Journal, 1: 21-22.

Svein, H.J., Gelety, J.E. (1964): On the surgical management of encapsulated subdural hematoma. A comparison of the results of membranectomy and simple evacuation. Journal of Neurosurgery, 21: 172-177.
Tabaddor, K., Shulman, K. (1977): Definitive treatment of chronic subdural hematoma by twist-drill craniostomy and closed-system drainage. Journal of Neurosurgery, 46: 220-226.

Tindall, G.T., Payne, N.S., O'Brien, M.S. (1976): Complications of surgery for subdural hematoma. Clinical Neurosurgery, 23: 465-482.

Tyson, G., Strachan, E., Newman, P., Winn, H.R., Butler, A., Jane, J. (1980): The role of craniectomy in the treatment of chronic subdural hematomas. Journal of Neurosurgery, 52: 776-781.

Vieth, R.G., Tindall, G.T., Odom, G.L. (1966): The use of tautalum dust as an adjunct in the postoperative management of subdural hematomas. Journal of Neurosurgery, 24: 514-519.

Yashon, D., White, R.J., Bryk, J.P., Dakters, J.G. (1971): Simplified supplementary treatment of chronic subdural fluid collections. Neurochirurgica, 14: 8-13. 